\title{
Optimizing Natural Deep Eutectic Solvent Citric Acid-Glucose Based Microwave- Assisted Extraction of Total Polyphenols Content from Eleutherine bulbosa (Mill.) Bulb
}

\author{
Bohari Yusuf ${ }^{1}$, Selvi Jumiatul Astati ${ }^{2}$, Mirhansyah Ardana $^{2}$, Herman $^{3}$, Arsyik Ibrahim $^{3}$, Laode Rijai ${ }^{3}$, \\ Firzan Nainu ${ }^{4}$, and Islamudin Ahmad ${ }^{2,3^{*}}$
}

${ }^{1}$ Department of Chemistry, Faculty of Mathematics and Natural Sciences, Universitas Mulawarman, Samarinda 75119, East Kalimantan, Indonesia

${ }^{2}$ Department of Pharmaceutical Sciences, Faculty of Pharmacy, Universitas Mulawarman, Samarinda 75119, East Kalimantan, Indonesia

${ }^{3}$ Pharmaceutical Research and Development Laboratory of FARMAKA TROPIS, Faculty of Pharmacy, Universitas Mulawarman, Samarinda 75119, East Kalimantan, Indonesia

${ }^{4}$ Faculty of Pharmacy, Hasanuddin University, Makassar 90245, South Sulawesi, Indonesia

\section{*Corresponding author:}

tel: $+62-81342205060$

email: islamudinahmad@farmasi.unmul.ac.id

Received: August 9, 2020

Accepted: December 18, 2020

DOI: $10.22146 / \mathrm{ijc} .58467$

\begin{abstract}
Application of natural deep eutectic solvent (NADES) citric acidglucose-based microwave-assisted extraction (MAE) method for total polyphenol content (TPC) enriches the use of Eleutherine bulbosa (Mill.) bulb more widely and commercially. Therefore, this study aims to optimize NADES citric acid-glucosebased MAE on the TPC from E. bulbosa bulbs using response surface methodology (RSM). In the present study, the dried sample of $\mathrm{E}$. bulbosa bulb was extracted using the NADES based MAE. Determination of TPC was conducted using FolinCiocalteau reagent and standard gallic acid, then measured using a UV-Vis spectrophotometer at $761 \mathrm{~nm}$. Extraction condition optimization of the NADES based MAE method was performed using RSM with Box Behnken Design (fourfactors-three-levels and 29 runs) on Design Expert v12. Based on the results study, the optimum condition extraction on the TPC enrichment was obtained at the NADES ratio (citric acid: glucose) $1: 1 \mathrm{~g} / \mathrm{g}$; solid-liquid ratio $1: 8 \mathrm{~g} / \mathrm{mL}$; extraction time of $15 \mathrm{~min}$; and $270 \mathrm{Watt}$ microwave power. The confirmation test and scaleup (50 g samples) were obtained with a $61.63 \pm 2.23 \mathrm{mg} \mathrm{GA} / \mathrm{g}$ sample.
\end{abstract}

Keywords: Eleutherine bulbosa Mill; microwave-assisted extraction; natural deep eutectic solvent; response surface methodology; total polyphenols content

\section{- INTRODUCTION}

Eleutherine bulbosa (E. bulbosa), known as Bawang Dayak, is a type of onion that grows wild in Kalimantan's tropical forests that has the potential to be developed and identified compounds that are efficacious [1]. E. bulbosa bulbs' chemical content includes tannin, flavonoids, quinones, and triterpenoid compound [2]. Besides, some compounds have been successfully isolated, including anthraquinone, naphthoquinone groups (such as elecanacine, eleutherine, elutherole, eleutherine), and eleuthosides A, B, C [3]. E. bulbosa bulbs are known to overcome various diseases such as cancer/cysts (breast/uterus), prostate, diabetes, gout, hypertension, gastrointestinal disturbances, cholesterol, goiter, bronchitis, stamina, and sexual disorders [4]. E. bulbosa bulb has enormous potential as a source of raw materials for natural-based medicines. This plant is abundant and easy to grow on Kalimantan island, but so far, commercial use is limited. Therefore, it is necessary to innovate for increasing the commercial use of this plant through the development of natural products with a green extraction approach. 
On the other hand, some studies on E. bulbosa have been widely reported, including the effect extraction method of this plant against oral glucose tolerance activity [5], sunscreen activity, and TLC profile [6], heat-assisted extraction of phenolic compound [7], and effect of ethanolic extraction of E. palmifolia tuber on blood glucose and insulin level [8]. However, the extraction of target secondary metabolites from E. bulbosa using a green solvent approach based on non-conventional extraction methods has not been reported.

The development of non-conventional extraction methods is recently increasing, such as the microwaveassisted extraction method (MAE). This method has advantages over other conventional methods because it is expected to shorten the extraction process, minimize the use of solvents, and save energy use through microwave energy in the irradiation process [9].

The choice of solvent and extraction method are the main factors that must be considered to obtain the extraction efficiency of the target compound from natural products. The utilization of Natural Deep Eutectic Solvent (NADES) has increased in recent years. NADES has many advantages as a solvent, such as requires low cost, chemically inert, adjustable viscosity, readily biodegradable, acceptable toxicity, and sustainability [1012]. NADES is a type of natural solvent in the form of a deep eutectic solvent, composed of a mixture component of primary metabolites (for example, sugar, amino acids, and organic acids). The right constituent of NADES will form a clear and stable liquid. In contrast, the inappropriate constituent components cause the liquid to be unstable, precipitable, and can return to solid form.

In this study, the selection of the composition of NADES in the form of citric acid and glucose is the right combination where glucose has hydrogen bonding acceptor (HBA) properties. Citric acid has hydrogen bonding donor (HBD) properties. Suppose both materials are fused at a specific temperature, forming a stable solution and ready to be used as a green solvent [13]. On the other hand, these two ingredients are pharmaceutical excipients that are safe for consumption, so it is hoped that the extract obtained can be readily consumed because not containing harmful organic solvents.
The combination of NADES with the nonconventional extraction method effectively extracts the desired target compound and minimizes the compound's undesirable extraction. Several studies have reported the success of NADES as an alternative solvent to replace conventional organic solvents, namely the experiment about extraction of flavonoid from Radix Scutellariae [14], extraction of phenol compounds from Cajanus cajan leaves [15], and extraction of polyphenols and caffeine from robusta coffee beans [16-17]. The optimization process of various factors that influence non-conventional extraction based on NADES is carried out using response surface methodology (RSM).

RSM is a mathematical and statistical tool that has a crucial role in designing, formulating, developing, and analyzing natural product research, mainly in the extraction method optimization process [18]. RSM has the advantage of studying the interaction between various factors on response [19-20]. In this study, boxBehnken design (BBD) with three-level fractional factorial was used to optimize the extraction condition of total polyphenol content (TPC) enrichment. The BBD is more economical and efficient than other factorial designs due to its ability to select points from a threelevel factorial arrangement without center point or factorial points. This design requires fewer points than different methods. The BBD has been used extensively to optimize some extraction conditions such as extraction time, extraction temperature, solvent types, solvent concentration, sample-solvent ratio, etc. [20].

Therefore, this study aims to optimize the condition of the NADES citric-glucose acid-based MAE method for the enrichment of TPC from E. bulbosa bulbs using RSM.

\section{- EXPERIMENTAL SECTION}

\section{Materials}

The samples of E. bulbosa bulb was collected from Samarinda, East Kalimantan, Indonesia. The specimen was authenticated and identified at Laboratory of Dendrology, Faculty of Forestry, Universitas Mulawarman, Samarinda, Indonesia. The fresh bulb was washed and cut into small pieces and dried using a dryer 
cabinet at $50-60{ }^{\circ} \mathrm{C}$. The citric acid $(100 \%$ pure food grade non-GMO) and glucose (food grade) were obtained from CV. Chlorogreen, Bandung, Indonesia. Gallic acid (analytical purity), Folin-Ciocalteau reagent, and sodium carbonate were purchased from Merck, Germany (through Elokarsa LLC, Indonesia). The quality test of the chemical purity was carried out before the experiment to ensure that the chemical quality was up to the specifications.

\section{Procedure}

\section{The procedure of NADES based MAE method}

The extraction process was carried out using NADES based MAE by referring to some previous studies [16,21-22], with some modifications adjusting the extraction conditions. Firstly, the composition of NADES (citric acid and glucose) was melted at $50-80{ }^{\circ} \mathrm{C}$ until forming a concentrated solution. The NADES solution slowly added distilled water in a ratio of 1:1, 3:1, and 5:1 g/g. Next, $5 \mathrm{~g}$ of $E$. bulbosa bulbs were mixed with NADES in a round bottom flask. Secondly, the extraction process was conducted using the MAE method, operated under various conditions, as shown in Table 1 . The extract solution and the residue were separated using a Buchner filter; The extract solution was kept in the refrigerator in a closed container until ready to analyze.

\section{Determination of total polyphenols content}

Determination of total polyphenols content (TPC) was done by spectrophotometry using the FolinCiocalteau reagent regarding some literature [23-24], with slight modification. Briefly, a $1 \mathrm{~mL}$ of sample and standard solution was put into a test tube, added with 5 $\mathrm{mL}$ of distilled water and $0.5 \mathrm{~mL}$ of Folin-Ciocalteu reagent. After $5 \mathrm{~min}$ of incubation, the other reagents such as $2 \mathrm{~mL}$ sodium carbonate and $1.5 \mathrm{~mL}$ distilled water was added. Absorbance was measured using a UV-Vis spectrophotometer at $761 \mathrm{~nm}$ (in this study, $761 \mathrm{~nm}$ was the maximum wavelength) after incubating the mixture of sample for $1 \mathrm{~h}$ at room temperature. The TPC in $\mathrm{mg}$ GAE/g samples were calculated using a linear regression equation obtained from gallic acid standard solutions at various concentrations (from 12.5 up to $200 \mu \mathrm{g} / \mathrm{mL}$ ), namely, $\mathrm{Y}=0.015+0.001559 \mathrm{X}$, with an $\mathrm{R}^{2}$ value of 0.9977 , where $\mathrm{Y}$ is absorbance, and $\mathrm{X}$ is TPC value.

\section{Design experimental of NADES based MAE optimization}

Optimization of the NADES based MAE condition for the TPC enrichment was optimized by response surface methodology (RSM). The optimization process was estimated the interaction between variables and factors (independent parameters) on the TPC value (dependent variable). Box Behnken Design (with fourfactor-three-level) was used for experimental design and requiring 29 experiments (with 1 block and 5 center points per block) for optimization extraction condition (in Table 1). A multilinear quadratic regression model was estimated according to the experimental data from different extraction conditions and TPC values using Design Expert v12 software licensed (Statease Inc. Minneapolis, MN, USA).

\section{- RESULTS AND DISCUSSION}

The study results from 29 runs obtained extraction conditions with the highest TPC of $85.251 \mathrm{mg} \mathrm{GAE} / \mathrm{g}$ (NADES ratio of 5:1 g/g, the solid-liquid ratio of 1:12 $\mathrm{g} / \mathrm{mL}$, extraction time of $10 \mathrm{~min}$ and microwave power of 270 Watt) and the lowest TPC of $27.091 \mathrm{mg} \mathrm{GAE} / \mathrm{g}$ (NADES ratio $3: 1 \mathrm{~g} / \mathrm{g}$, a solid-liquid ratio of $1: 8$, extraction time of $5 \mathrm{~min}$ and 270 Watt of microwave power), as shown in Table 2. The determination of TPC

Table 1. Experimental design of response surface methodology with box Behnken design using NADES citric acidglucose as a green solvent

\begin{tabular}{ccccccc}
\hline \multirow{2}{*}{ No. } & \multirow{2}{*}{ Independent Variables } & \multirow{2}{*}{ Unit } & \multirow{2}{*}{ Symbol } & \multicolumn{3}{c}{ Factor Levels } \\
\cline { 5 - 7 } & & & Low $(-1)$ & Medium $(0)$ & High $(+1)$ \\
\hline 1 & NADES (citric acid-glucose) ratio & $\mathrm{g} / \mathrm{g}$ & $\mathrm{X}_{1}$ & $1: 1$ & $3: 1$ & $5: 1$ \\
2 & Liquid-Solid Ratio & $\mathrm{mL} / \mathrm{g}$ & $\mathrm{X}_{2}$ & $8: 1$ & $10: 1$ & $12: 1$ \\
3 & Extraction Time & $\mathrm{min}$ & $\mathrm{X}_{3}$ & 5 & 10 & 15 \\
4 & Microwave Power & Watts & $\mathrm{X}_{4}$ & 90 & 270 & 450 \\
\hline
\end{tabular}


Table 2. Experimental values of TPC of the E. bulbosa bulb extract obtained by NADES-MAE at various conditions

\begin{tabular}{|c|c|c|c|c|c|c|}
\hline \multirow[t]{2}{*}{ Run } & \multirow{2}{*}{$\begin{array}{l}\text { NADES Ratio } \\
(\mathrm{g} / \mathrm{mL}) \\
\mathrm{X}_{1}\end{array}$} & \multirow{2}{*}{$\begin{array}{c}\text { Liquid-Solid } \\
\text { ratio }(\mathrm{g} / \mathrm{g}) \\
\mathrm{X}_{2}\end{array}$} & \multirow{2}{*}{$\begin{array}{c}\begin{array}{c}\text { Extraction Time } \\
(\mathrm{min})\end{array} \\
\mathrm{X}_{3}\end{array}$} & \multirow{2}{*}{$\begin{array}{c}\text { Microwave Power } \\
\text { (Watt) } \\
\mathrm{X}_{4}\end{array}$} & \multicolumn{2}{|c|}{$\begin{array}{c}\text { TPC } \\
\text { (mg GAE/g sample) }\end{array}$} \\
\hline & & & & & Actual & Predicted \\
\hline 1 & $3: 1(0)$ & $12: 1(+1)$ & $10(0)$ & $450(+1)$ & 38.70 & 43.37 \\
\hline 2 & $5: 1(+1)$ & $10: 1(0)$ & $5(-1)$ & $270(0)$ & 68.42 & 69.69 \\
\hline 3 & $1: 1(-1)$ & $12: 1(+1)$ & $10(0)$ & $270(0)$ & 46.71 & 43.17 \\
\hline 4 & $3: 1(0)$ & $8: 1(-1)$ & $15(+1)$ & $270(0)$ & 38.58 & 40.39 \\
\hline 5 & $3: 1(0)$ & $10: 1(0)$ & $5(-1)$ & $450(+1)$ & 41.93 & 38.33 \\
\hline 6 & $5: 1(+1)$ & $10: 1(0)$ & $15(+1)$ & $270(0)$ & 77.24 & 77.82 \\
\hline 7 & $3: 1(0)$ & $10: 1(0)$ & $10(0)$ & $270(0)$ & 39.77 & 41.61 \\
\hline 8 & $3: 1(0)$ & $8: 1(-1)$ & $10(0)$ & $450(+1)$ & 37.68 & 35.63 \\
\hline 9 & $3: 1(0)$ & $12: 1(+1)$ & $5(-1)$ & $270(0)$ & 35.64 & 38.86 \\
\hline 10 & $1: 1(-1)$ & $10: 1(0)$ & $15(+1)$ & $270(0)$ & 51.13 & 49.27 \\
\hline 11 & $3: 1(0)$ & $8: 1(-1)$ & $10(0)$ & $90(-1)$ & 32.75 & 27.49 \\
\hline 12 & $3: 1(0)$ & $10: 1(0)$ & $10(0)$ & $270(+1)$ & 32.86 & 41.61 \\
\hline 13 & $3: 1(0)$ & $10: 1(0)$ & $15(+1)$ & $450(+1)$ & 41.28 & 42.62 \\
\hline 14 & $5: 1(+1)$ & $10: 1(0)$ & $10(0)$ & $450(+1)$ & 75.67 & 74.91 \\
\hline 15 & $3: 1(0)$ & 10:1 (0) & $10(0)$ & $270(0)$ & 49.50 & 41.61 \\
\hline 16 & $1: 1(-1)$ & $10: 1(0)$ & $10(0)$ & $90(-1)$ & 31.28 & 37.08 \\
\hline 17 & $1: 1(-1)$ & $8: 1(-1)$ & $10(0)$ & $270(0)$ & 48.18 & 48.54 \\
\hline 18 & $3: 1(0)$ & $10: 1(0)$ & $5(-1)$ & $90(-1)$ & 31.00 & 25.21 \\
\hline 19 & $3: 1(0)$ & $12: 1(+1)$ & $10(0)$ & $90(-1)$ & 28.22 & 29.69 \\
\hline 20 & $3: 1(0)$ & $8: 1(-1)$ & $5(-1)$ & $270(0)$ & 27.09 & 33.15 \\
\hline 21 & $3: 1(0)$ & $12: 1(+1)$ & $15(+1)$ & $270(0)$ & 45.63 & 44.62 \\
\hline 22 & $5: 1(+1)$ & $10: 1(0)$ & $10(0)$ & $10(-1)$ & 57.54 & 62.18 \\
\hline 23 & $1: 1(-1)$ & $10: 1(0)$ & $5(-1)$ & $270(0)$ & 45.55 & 44.39 \\
\hline 24 & $5: 1(+1)$ & $8: 1(-1)$ & $10(0)$ & $270(0)$ & 66.04 & 65.12 \\
\hline 25 & $3: 1(0)$ & $10: 1(0)$ & $15(+1)$ & $90(-1)$ & 34.77 & 33.92 \\
\hline 26 & $1: 1(-1)$ & $10: 1(0)$ & $10(0)$ & $450(+1)$ & 45.76 & 46.16 \\
\hline 27 & $5: 1(+1)$ & $12: 1(+1)$ & $10(0)$ & $270(0)$ & 85.25 & 80.25 \\
\hline 28 & $3: 1(0)$ & $10: 1(0)$ & $10(0)$ & $270(0)$ & 44.62 & 41.61 \\
\hline 29 & $3: 1(0)$ & $10: 1(0)$ & $10(0)$ & $270(0)$ & 41.31 & 41.61 \\
\hline
\end{tabular}

in extracts was carried out based on the standard gallic acid obtained. Gallic acid acts as a standard because it is a derivative of hydroxybenzoic acid, which is a simple phenol acid that is pure and stable [16,23-24]. The concentration of gallic acid used was at 12.5 to $200 \mathrm{ppm}$. Gallic acid analysis was performed using a UV-Vis spectrophotometer, which produced the equation $\mathrm{Y}=$ $0.015+0.001559 \mathrm{X}$ with a correlation coefficient $\left(\mathrm{R}^{2}\right)$ of 0.997, where $\mathrm{Y}$ is the absorbance. At the same time, the $\mathrm{X}$ value is the TPC value. The equation used to calculate sample levels with various pre-determined factor conditions using RSM.

The absorbance data was measured using a spectrophotometer at $761 \mathrm{~nm}$. The TPC values were calculated using a regression equation formula from a standard calibration curve, then the TPC value obtained in $\mathrm{mg} \mathrm{GAE/g} \mathrm{samples.} \mathrm{All} \mathrm{data} \mathrm{were} \mathrm{analyzed} \mathrm{using} \mathrm{the}$ Design Expert 12 licensed software to determine the optimum conditions for the enrichment of TPC in this study. In Table 3, the standard quadratic model was 
suitable for TPC's response with a value of $\mathrm{p}<0.0001$ ( $<$ $0.01 \%$ ), which shows the probability of a model error of less than $5 \%$ or means the quadratic model has a significant effect response to the TPC. Next, an ANOVA analysis was performed on the chosen model. If the value of "prob> F" is lower than 0.05 , then the relationship becomes significant, while for the value of "prob> F" higher than 0.1, then the relationship becomes not significant.

The suggested standard quadratic model was based on the insignificant value in the lack of fit with the predicted $R^{2}$ value lower than the adjusted $R^{2}$ value. However, with a predictive $\mathrm{R}^{2}$ of 0.7353 , this is still in reasonable agreement with the adjusted $R^{2}$ of 0.9051 . The predicted $\mathrm{R}^{2}$ and the adjusted $\mathrm{R}^{2}$ should be within 0.20 of each other. Otherwise, there may be a problem with either the data or the model. The regular $\mathrm{R}^{2}$ can be artificially inflated by merely adding terms to the model, even if the terms are not statistically significant. The adjusted $R^{2}$ plateaus when insignificant terms are added to the model, and the predicted $R^{2}$ will decrease when there are too many insignificant terms. A rule of thumb is that the adjusted and predicted $R^{2}$ values should be within 0.2 of each other. For the optimal designs, the mixture polynomials can be reduced before point selection. Reducing the number of coefficients reduces the number of model points required and changes the variable's selection criterion [25-27].

Table 4 shows the best reduced quadratic model based on the results of the analysis of variance. The model F-value of 34.39 and p-value of $<0.0001$ less than 0.050 indicate the model terms are significant. There is only a $0.01 \%$ chance of an F-value occurring due to interference. In this case, $\mathrm{X}_{1}, \mathrm{X}_{3}, \mathrm{X}_{4}, \mathrm{X}_{1} \mathrm{X}_{2}, \mathrm{X}_{1}^{2}, \mathrm{X}_{4}{ }^{2}$ are significant model terms. The "Lack of Fit" F-value of 0.47 implies the "Lack of Fit" is not significant relative to the pure error. There is an $87.43 \%$ chance that a "Lack of Fit" F-value this large could occur due to noise. Nonsignificant "Lack of Fit" is right. This value indicates that all four factor have a significant relationship with the

Table 3. The selection of mathematical model analysis for optimization

\begin{tabular}{lccccc}
\hline \multicolumn{1}{c}{ Source } & $\begin{array}{c}\text { Sequential } \\
\text { p-value }\end{array}$ & $\begin{array}{c}\text { Lack of Fit } \\
\text { p-value }\end{array}$ & $\begin{array}{c}\text { Adjusted } \\
\text { R-Squared }\end{array}$ & $\begin{array}{c}\text { Predicted } \\
\text { R-Squared }\end{array}$ & Recommendation \\
\hline Linear & 0.0082 & 0.0714 & 0.3274 & 0.1163 & \\
Two-Factor Interaction & 0.9948 & 0.0420 & 0.1335 & -0.7595 & Suggested \\
Quadratic & $<0.0001$ & 0.7209 & 0.8739 & 0.7353 & Aliased \\
Cubic & 0.8152 & 0.3899 & 0.8246 & -1.0697 & \\
\hline
\end{tabular}

Table 4. Analysis of variance

\begin{tabular}{lrrrrrr}
\hline \multicolumn{1}{c}{ Source } & $\begin{array}{r}\text { Sum of } \\
\text { Squares }\end{array}$ & $\mathrm{df}$ & Mean Square & F-value & p-value & \\
\hline Model & 6016.31 & 8 & 752.04 & 34.39 & $<0.0001$ & Significant \\
$\mathrm{X}_{1}$ & 2174.97 & 1 & 2174.97 & 99.46 & $<0.0001$ & \\
$\mathrm{X}_{2}$ & 74.18 & 1 & 74.18 & 3.39 & 0.0804 & \\
$\mathrm{X}_{3}$ & 126.69 & 1 & 126.69 & 5.79 & 0.0259 & \\
$\mathrm{X}_{4}$ & 357.00 & 1 & 357.00 & 16.33 & 0.0006 & \\
$\mathrm{X}_{1} \mathrm{X}_{2}$ & 106.98 & 1 & 106.98 & 4.89 & 0.0388 & \\
$\mathrm{X}_{2} \mathrm{X}_{4}$ & 7.69 & 1 & 7.69 & 0.3516 & 0.5598 & \\
$\mathrm{X}_{1}{ }^{2}$ & 2691.64 & 1 & 2691.64 & 123.09 & $<0.0001$ & \\
$\mathrm{X}_{4}{ }^{2}$ & 210.73 & 1 & 210.73 & 9.64 & 0.0056 & \\
Residual & 437.36 & 20 & 21.87 & & & \\
Lack of Fit & 285.90 & 16 & 17.87 & 0.4719 & 0.8743 & not significant \\
Pure Error & 151.46 & 4 & 37.86 & & & \\
Cor Total & 6453.67 & 28 & & & & \\
\hline
\end{tabular}


response [28-29]. The independent variable of $X_{1}$ and $X_{4}$ was less than 0.05 , indicating statistically significant extraction results. Meanwhile, the independent variables $\mathrm{X}_{2}$ and $\mathrm{X}_{3}$ were greater than 0.05 , indicating that the variable was not significant to the extraction results. But overall, the interaction between variables influences response.

In Table 5, the coefficient estimates represent the expected change in response per unit change in factor value when all remaining factors are held constant. The intercept in an orthogonal design is the overall average response of all the runs. The coefficients are adjustments around that average based on the factor settings. When the factors are orthogonal, the VIFs are 1; VIFs greater than 1 indicate multi-collinearity. The higher the VIF, the more severe the correlation of factors. As a rough rule, VIFs less than 10 are tolerable.

The equation formula obtained was $\mathrm{Y}=40.32+$ $13.46 \mathrm{X}_{1}+2.49 \mathrm{X}_{2}+3.25 \mathrm{X}_{3}+5.45 \mathrm{X}_{3}+5.17 \mathrm{X}_{1} \mathrm{X}_{2}+1.39 \mathrm{X}_{2} \mathrm{X}_{4}$ $+19.75 \mathrm{X}_{1}^{2}-5.90 \mathrm{X}_{4}^{2}$ with $\mathrm{R}^{2}$ value of 0.9322 with the predicted $R^{2}$ of 0.8580 was in reasonable agreement with the adjusted $\mathrm{R}^{2}$ of 0.9051 , the difference was less than 0.2 . Adequate precision measures the signal to noise ratio. Greater than four ratios were desirable. The ratio of 21,150 indicates an adequate signal. This model can be used to navigate the design space. In this equation, $\mathrm{Y}$ is the TPC value, where $X_{1}$ is the NADES ratio $(g / g), X_{2}$ is the solid-liquid ratio $(\mathrm{g} / \mathrm{mL}), \mathrm{X}_{3}$ is extraction time ( $\left.\mathrm{min}\right)$, and $\mathrm{D}$ is microwave power (Watt). The equation in terms of actual factors can be used to make predictions about each factor that has given levels' response. Here, the levels should be specified in the original units for each factor. This equation should not determine each factor's relative impact because the coefficients are scaled to accommodate the units of each factor, and the intercept is not at the center of the design space [28-29].

From this equation, the optimum conditions were obtained according to the results of RSM analysis, including 1:1 g/g NADES ratio (citric acid: glucose), 1:8 $\mathrm{g} / \mathrm{mL}$ solid-liquid ratio, extraction time of $15 \mathrm{~min}$, and 270 Watt microwave power with predicted the TPC of $51.09 \pm 4.68 \mathrm{mg}$ GAE$/ \mathrm{g}$ sample. The confirmation test and scale-up using ten times the number of samples $(50 \mathrm{~g})$ were obtained with a $61.63 \pm 2.23 \mathrm{mg} \mathrm{GAE} / \mathrm{g}$ sample, which showed that the TPC produced was within the tolerance interval (TI) range with 95\% TI low and $95 \%$ IT high. The TI means that the extraction process to obtain TPC's response compared to the extraction conditions predicted by the program is entirely consistent. Each parameter's value is determined by considering the efficiency of the results obtained in the extraction process using time, energy, and solvent consumption.

Based on the above findings, the use of NADES with the composition of citric acid and glucose is more effective than conventional methods. Munaeni et al. reported a TPC of $2.5 \mathrm{mg} \mathrm{GAE} / \mathrm{g}$ from E. bulbosa bulbs extracted by maceration using $96 \%$ ethanol [30]. At the

Table 5. Coefficient estimate, standard error, confidence interval, and VIF of the reduced quadratic model

\begin{tabular}{lcccccc}
\hline Factor & $\begin{array}{c}\text { Coefficient } \\
\text { Estimate }\end{array}$ & $\mathrm{df}$ & $\begin{array}{c}\text { Standard } \\
\text { Error }\end{array}$ & $\begin{array}{c}\text { 95\% Confidence } \\
\text { Interval (CI) Low }\end{array}$ & $\begin{array}{c}\text { 95\% Confidence } \\
\text { Interval (CI) High }\end{array}$ & $\begin{array}{c}\text { Variance Inflation } \\
\text { Factor (VIF) }\end{array}$ \\
\hline Intercept & 40.32 & 1 & 1.41 & 37.38 & 43.27 & \\
$\mathrm{X}_{1}$ & 13.46 & 1 & 1.35 & 10.65 & 16.28 & 1.0000 \\
$\mathrm{X}_{2}$ & 2.49 & 1 & 1.35 & -0.3296 & 5.30 & 1.0000 \\
$\mathrm{X}_{3}$ & 3.25 & 1 & 1.35 & 0.4332 & 6.07 & 1.0000 \\
$\mathrm{X}_{4}$ & 5.45 & 1 & 1.35 & 2.64 & 8.27 & 1.0000 \\
$\mathrm{X}_{1} \mathrm{X}_{2}$ & 5.17 & 1 & 2.34 & 0.2942 & 10.05 & 1.0000 \\
$\mathrm{X}_{2} \mathrm{X}_{4}$ & 1.39 & 1 & 2.34 & -3.49 & 6.26 & 1.0000 \\
$\mathrm{X}_{1}{ }^{2}$ & 19.75 & 1 & 1.78 & 16.03 & 23.46 & 1.02 \\
$\mathrm{X}_{4}{ }^{2}$ & -5.53 & 1 & 1.78 & -9.24 & -1.81 & 1.02 \\
\hline
\end{tabular}


same time, Shi et al. reported a TPC of $1.4 \mathrm{mg} \mathrm{GAE} / \mathrm{g}$ of E. bulbosa bulbs [34]. Those previous extraction studies show that NADES (citric acid-glucose) combined with the MAE method can be an alternative solvent to replace conventional solvents and extraction methods in certain conditions effectively, quickly, and efficiently environmentally friendly.

\section{- CONCLUSION}

The application of the green extraction approach in separating target secondary metabolites from natural products (mainly from plants) continues to experience a significant increase. The use of NADES combined with the MAE method has been successfully optimized using RSM for TPC enrichment. Optimum conditions obtained were 1:1 g/g NADES ratio (citric acid: glucose), 1:8 g/mL solid-liquid ratio, extraction time of $15 \mathrm{~min}$, and $270 \mathrm{Watt}$ microwave power, with the confirmed TPC value of 61.63 $\pm 2.23 \mathrm{mg} \mathrm{GAE} / \mathrm{g}$ sample.

\section{- ACKNOWLEDGMENTS}

The authors wish to acknowledge the support Rector of Universitas Mulawarman and Head Laboratory of Pharmaceutical Science and Technology, Faculty of Pharmacy, Universitas Mulawarman for providing facilities for the study.

\section{- AUTHOR CONTRIBUTIONS}

All author was involved in this study. BY, I.A, SJA, and MA conducted the experiment, He, AI, LR, and FN conducted the DFT calculations, BY, I.A and FN wrote and revised the manuscript. All authors agreed to the final version of this manuscript.

\section{- REFERENCES}

[1] Kuntorini, E.M., Dewi, M., and Misrina, 2016, Anatomical structure and antioxidant activity of red bulb plant (Eleutherine americana) on different plant age, Biodiversitas, 17 (1), 229-233.

[2] Insanu, M., Kusmardiyani, S., and Hartati, R., 2014, Recent studies on phytochemicals and pharmacological effects of Eleutherine americana Merr., Procedia Chem., 13, 221-228.

[3] Singab, A.N.B., Ayoub, I.M., El-Shazly, M., Korinek,
M., Wu, T.Y., Cheng, Y.B., Chang, F.R., and Wu, Y.C., 2016, Shedding the light on Iridaceae: Ethnobotany, phytochemistry and biological activity, Ind. Crops Prod., 92, 308-335.

[4] Naspiah, N., Iskandar, Y., and Moektiwardoyo, M., 2014, Artikel ulasan: Bawang tiwai (Eleutherine americana Merr.), tanaman multiguna, Indones. J. Appl. Sci., 4 (2), 18-30.

[5] Ahmad, I., Ambarwati, N.S.S., Indriyanti, N., Sastyarina, Y., Rijai, L., and Mun'im, A., 2018, Oral glucose tolerance activity of Bawang Dayak (Eleutherine palmifolia L. Merr.) bulbs extract based on the use of different extraction method, Pharmacogn. J., 10 (1), 49-54.

[6] Ahmad, I., Arifuddin, M., and Rijai, L., 2016, The effect of extraction methods of bawang Dayak (Eleutherine palmifolia (L.) Merr) against TLC profiles and sunscreen activities, Int. J. PharmTech Res., 9 (9), 428-436.

[7] Kamarudin, A.A., Mohd. Esa, N., Saad, N., Sayuti, N.H., and Ab. Razak, N.A., 2019, Heat assisted extraction of phenolic compounds from Eleutherine bulbosa (Mill.) bulb and its bioactive profiles using response surface methodology, Ind. Crops Prod., 144, 112064.

[8] Hasni, Y., Aminah, D., and Tri, W., 2019, The effect of ethanolic extract of Dayak onion (Eleutherine palmifolia (L) Merr) tuber on blood glucose and insulin level of strepzotocin-induced diabetic wistar rat, Asian J. Pharm. Res. Dev., 7 (4), 38-42.

[9] Ahmad, I., Yanuar, A., Mulia, K., and Mun'im, A., 2018, Ionic liquid-based microwave-assisted extraction: Fast and green extraction method of secondary metabolites on medicinal plant, Pharmacogn. Rev., 12 (23), 20-26.

[10] Dai, Y., Witkamp, G.J., Verpoorte, R., and Choi, Y.H., 2013, Natural deep eutectic solvents as a new extraction media for phenolic metabolites in Carthamus tinctorius L., Anal. Chem., 85 (13), 6272-6278.

[11] Dai, Y., Jin, R., Verpoorte, R., Lam, W., Cheng, Y.C., Xiao, Y., Xu, J., Zhang, L., Qin, X.M., and Chen, S., 2020, Natural deep eutectic characteristics of honey 
improve the bioactivity and safety of traditional medicines, J. Ethnopharmacol., 250, 112460.

[12] Vanda, H., Dai, Y., Wilson, E.G., Verpoorte, R., and Choi, Y.H., 2018, Green solvents from ionic liquids and deep eutectic solvents to natural deep eutectic solvents, Comptes Rendus Chim., 21 (6), 628-638.

[13] Mulia, K., Fauzia, F., and Krisanti, E.A., 2019, Polyalcohols as hydrogen-bonding donors in choline chloride-based deep eutectic solvents for extraction of xanthones from the pericarp of Garcinia mangostana L., Molecules, 24 (3), 636.

[14] Wei, Z.F., Wang, X.Q., Peng, X., Wang, W., Zhao, C.J., $\mathrm{Zu}$, Y.G., and $\mathrm{Fu}, \mathrm{Y} ., 2015$, Fast and green extraction and separation of main bioactive flavonoids from Radix Scutellariae, Ind. Crops Prod., 63, 175-181.

[15] Wei, Z., Qi, X., Li, T., Luo, M., Wang, W., Zu, Y., and $\mathrm{Fu}, \mathrm{Y} ., 2015$, Application of natural deep eutectic solvents for extraction and determination of phenolics in Cajanus cajan leaves by ultraperformance liquid chromatography, Sep. Purif. Technol., 149, 237-244.

[16] Ahmad, I., Pertiwi, A.S., Kembaren, Y.H., Rahman, A., and Mun'im, A., 2018, Application of natural deep eutectic solvent-based ultrasonic assisted extraction of total polyphenolic and caffeine content from coffe beans (Coffea beans L.) for instant food products, J. Appl. Pharm. Sci., 8 (8),138-143.

[17] Yuniarti, E., Saputri, F.C., and Mun'im, A., 2019, Application of the natural deep eutectic solvent choline chloride-sorbitol to extract chlorogenic acid and caffeine from green coffee beans (Coffea canephora), J. Appl. Pharm. Sci., 9 (3), 82-90.

[18] Dean, A., Voss, D., and Draguljic, D., 2017, "Response surface methodology" in Design and Analysis of Experiments, Springer, Cham, 565-614.

[19] Yolmeh, M., and Jafari, S.M., 2017, Applications of response surface methodology in the food industry processes, Food Bioprocess Technol., 10 (3), 413-433.

[20] Riswanto, F.D.O., Rohman, A., Pramono, S., and Martono, S., 2019, Application of response surface methodology as mathematical and statistical tools in natural product research, J. Appl. Pharm. Sci., 9 (10), 125-133.

[21] Gomez, F.J.V., Espino, M., Fernández, M.A., and Silva, M.F., 2018, A greener approach to prepare natural deep eutectic solvents, ChemistrySelect, 3 (22), 6122-6125.

[22] González, C.G., Mustafa, N.R., Wilson, E.G., Verpoorte, R., and Choi, Y.H., 2018, Application of natural deep eutectic solvents for the "green" extraction of vanillin from vanilla pods, Flavour Fragrance J., 33 (1), 91-96.

[23] Sánchez-Rangel, J., Benavides, J., Heredia, J.B., Cisneros-Zevallos, L., and Jacobo-Velázquez, D.A., 2013, The Folin-Ciocalteu assay revisited: Improvement of its specificity for total phenolic content determination, Anal. Methods, 5 (21), 5990-5999.

[24] Bobo-García, G., Davidov-Pardo, G., Arroqui, C., Vírseda, P., Marín-Arroyo, M., and Navarro, M., 2014, Intra-laboratory validation of microplate methods for total phenolic content and antioxidant activity on polyphenolic extracts, and comparison with conventional spectrophotometric methods, $J$. Sci. Food Agric., 95 (1), 204-209.

[25] Brusco, M.J., Voorhees, C.M., Calantone, R.J., Brady, M.K., and Steinley, D., 2019, Integrating linear discriminant analysis, polynomial basis expansion, and genetic search for two-group classification, Commun. Stat.- Simul. Comput., 48 (6), 1623-1636.

[26] Chelladuai, S.J.S., Murugan, K., Ray, A.P., Upadhyaya, M., Narasimharaj, V., and Gnanasekaran, S., 2021, Optimization of process parameters using response surface methodology: A review, Mater. Today: Proc., 37 (2), 1301-1304.

[27] Salim, N., Santhiagu, A., and Joji, K., 2019, Process modeling and optimization of high yielding Lmethioninase from a newly isolated Trichoderma harzianum using response surface methodology and artificial neural network coupled genetic algorithm, Biocatal. Agric. Biotechnol., 17, 299-308. [28] Mäkelä, M., 2017, Experimental design and 
response surface methodology in energy applications: A tutorial review, Energy Convers. Manage., 151, 630-640.

[29] Alam, S.T., and Amin, M.A., 2020, Determining optimum design parameters of foldadble product using response surface and genetic algorithm,
Engineering, 12, 839-850.

[30] Shi, P., Du, W., Wang, Y., Teng, X., Chen, X., and Ye, L., 2019, Total phenolic, flavanoid content, and antioxidant activity of bulbs, leaves, and flowers made form Eleutherine bulbosa (Mill.) Urb., Food Sci. Nutr., 7 (1), 148-154. 